Article

\title{
Admixing Chaff with Straw Increased the Residues Collected without Compromising Machinery Efficiencies
}

\author{
Alessandro Suardi ${ }^{1}{ }^{\oplus}$, Sergio Saia ${ }^{1, *}\left(\mathbb{C}\right.$, Walter Stefanoni ${ }^{1}{ }^{\circledR}$, Carina Gunnarsson ${ }^{2}$, Martin Sundberg ${ }^{2}$ \\ and Luigi Pari ${ }^{1}$ D \\ 1 Council for Agricultural Research and Economics (CREA)-Research Centre for Engineering and Agro-Food \\ Processing (CREA-IT), Via della Pascolare, 16 - 00015 Monterotondo Scalo (Rome) Italy; \\ alessandro.suardi@crea.gov.it (A.S.); walter.stefanoni@crea.gov.it (W.S.); luigi.pari@crea.gov.it (L.P.) \\ 2 Research Institutes of Sweden (RISE), Ultunaallén 4, 75651 Uppsala, Sweden; carina.gunnarsson@ri.se (C.G.); \\ martin.sundberg@ri.se (M.S.) \\ * Correspondence: sergio.saia@crea.gov.it
}

Received: 18 February 2020; Accepted: 2 April 2020; Published: 7 April 2020

check for updates

\begin{abstract}
The collection of residues from staple crop may contribute to meet EU regulations in renewable energy production without harming soil quality. At a global scale, chaff may have great potential to be used as a bioenergy source. However, chaff is not usually collected, and its loss can consist of up to one-fifth of the residual biomass harvestable. In the present work, a spreader able to manage the chaff (either spreading [SPR] on the soil aside to the straw swath or admixed [ADM] with the straw) at varying threshing conditions (with either 1 or 2 threshing rotors [1R and 2R, respectively] in the combine, which affects the mean length of the straw pieces). The fractions of the biomass available in field (grain, chaff, straw, and stubble) were measured, along with the performances of both grain harvesting and baling operations. Admixing chaff allowed for a slightly higher amount of straw fresh weight baled compared to SPR (+336 kg straw ha $\left.{ }^{-1}\right)$, but such result was not evident on a dry weight basis. At the one time, admixing chaff reduced the material capacity of the combine by $12.9 \%$. Using $2 \mathrm{R}$ compared to $1 \mathrm{R}$ strongly reduced the length of the straw pieces, and increased the bale unit weight; however, it reduced the field efficiency of the grain harvesting operations by $11.9 \%$. On average, the straw loss did not vary by the treatments applied and was $44 \%$ of the total residues available (computed excluding the stubble). In conclusion, admixing of chaff with straw is an option to increase the residues collected without compromising grain harvesting and straw baling efficiencies; in addition, it can reduce the energy needs for the bale logistics. According to the present data, improving the chaff collection can allow halving the loss of residues. However, further studies are needed to optimise both the chaff and the straw recoveries.
\end{abstract}

Keywords: bioresource; cereals; commodity; harvest index; staple foods; triticum; wheat

\section{Introduction}

The global cultivation of wheat involves an area of more than 225 Mha for total grain production of $684 \mathrm{Mt} \mathrm{y}^{-1}$ [1]. Wheat cropping is a valuable source of biomass residue, mainly as straw, suitable for livestock as bedding, or as raw material for chemical applications, as reported by Scarlat et al. [2]. In addition, the use of vegetable biomass for more environmentally-friendly energy production is strongly supported by the new European policies [3], which encourage the use of crop residues, instead of dedicated crops to reduce the land use by the non-food crops. Since the demand for energy is increasing, the bio sources being currently exploited are unable to meet the new targets set by the EU 2030 framework for climate and energy policies [4,5]. Therefore, the capacity to retrieve as much residual biomass as possible has to be fostered. Chaff, which is the lightest and tiniest fractions 
resulting from wheat harvesting, could be included in straw collection in order to increase the total amount of biomass collected. According to McCartney et al. [6], chaff accounts, on average, for 17\% $(w / w)$, compared to grain production. Therefore, considering the $138 \mathrm{Mt}$ and $684 \mathrm{Mt}$ of wheat and spelt harvested yearly in Europe and globally, respectively [1], more than $23 \mathrm{Mt} \mathrm{yr}^{-1}$ and $116 \mathrm{Mt} \mathrm{yr}^{-1}$ of chaff are potentially available for harvesting in Europe and globally, respectively. Retrieving chaff from cereal crops could also have indirect positive effects on agricultural inputs $[7,8]$. Indeed, according to Rush [9], under favorable conditions, the presence of chaff in soil may represent a good substrate for saprophytic development, whereas Shirtliffe \& Entz [10] highlighted the positive contribution of chaff removal in curbing weed seed availability in the soil. Besides, the additional biomass removed from soils may not lead to impoverishment of the stabile fraction of the soil organic carbon (SOC), since most of it likely derives from the decaying root system, which remains untouched [11]. Indeed, leaving plant residues in soil can reduce the loss of soil sediment and fertility; however, it has been shown that such an effect can be strongly variable [12]. In addition, it was clearly highlighted that a reduction of soil tillage is more likely to reduce the loss of soil organic carbon and soil fertility than maintenance of the soil cover [13].

Despite the chaff potential for various uses, most modern combine harvesters lack of a chaff recovery systems, unless specific equipment is installed [14]. The possible exploitation of agricultural residues for non-food purposes, as wheat chaff, has stimulated machine constructors to develop new systems. Some systems are already on the market and others are in the prototype stage [15]. Regardless of the brand, the common strategy for chaff recovery systems is to catch the chaff at the end of the cleaning shoe system of the combine harvester before it falls to the ground and get lost. Residues collection may not be economically and energetically feasible when crop yields are low [16,17], especially if the transport cost can offset the higher biomass collected when collecting the chaff separately from the straw or transporting it without a baling procedure [18]. The present study aimed to test a strategy to increase the total amount of residual biomass collected by recovering wheat crop chaff by admixing it with straw. This was studied in a two-year experiment using a Rekordverken Combi system installed on a hybrid combine harvester (2017) and a conventional combine harvester (2019). In addition, the overall performance of the machines involved (the grain combine harvester and the baler) in the biomass supply chain were measured. The present experiment was conducted in the framework of the H2020 AGROinLOG project [19], whose aim is to implement and demonstrate the technical and economic feasibility of integration of biomass logistic centres (IBLCs) for food and non-food products into the agro-industry sectors. In particular, there is increasing interest worldwide for more biomass residues available for the production of second generation ethanol. This could be achieved through the use of equipment commonly used in agriculture that does not require large initial investment, such as the spreader tested in this study.

\section{Materials and Methods}

\subsection{Experimental Design}

A field experiment was conducted in two cropping seasons in Sweden. The first cropping season was in 2017 near Vattholma (Uppsala region, SE) $\left(60^{\circ} 00^{\prime} 54.0^{\prime \prime} \mathrm{N} 17^{\circ} 39^{\prime} 19.1^{\prime \prime} \mathrm{E}\right)$; the second cropping season was in 2019 near Alunda (Uppsala region, SE) $\left(60^{\circ} 05^{\prime} 29.7^{\prime \prime} \mathrm{N} 18^{\circ} 07^{\prime} 04.7^{\prime \prime} \mathrm{E}\right)$.

The soil of the area under study has a silty clay loam texture. In Vattholma, the soil has $\mathrm{pH}=6.2$, clay content of $32 \%$, silt content of $66.6 \%$, and $1.8 \%$ of soil organic matter. In Alunda, soil has $\mathrm{pH}=7.8$, clay content of $39 \%$, and $4.9 \%$ of soil organic matter.

The elite winter wheat cultivar Julius was sown in early September in both cropping seasons at a rate of 170-180 kg seed/ha. In Alunda, the preceding crop was pea, and pea straw was removed. The winter wheat was treated with fungicide and fertilized with $100 \mathrm{~kg}$ MAP/ha (NP 12-23), $140 \mathrm{~kg}$ Axan/ha (NS 27-4), and $30 \mathrm{t}$ of liquid manure ha ${ }^{-1}(1.5-2 \mathrm{~kg} \mathrm{~N} / \mathrm{t})$. No additional information is available for Vattholma. 
In both cropping seasons, the experiments were arranged as a randomized block design with three replicates. There were two factors in the experiment: chaff mixing $(\mathrm{CM})$ with straw and number or rollers $(\mathrm{RN})$ used in the combine to thresh the grain from the chaff and straw. Chaff mixing with straw consisted of two treatments: either chaff admixed with straw in the combine (ADM) before the residue release by the combine or not i.e., chaff spread on the soil before straw release without mixing with straw in the combine (SPR). Thus, in theory, SPR consisted of a deposition on the soil of the chaff below the straw swath, whereas ADM consisted of a deposition in the soil of a mix of straw + chaff swath. The number of rotors used in the combine to thresh the grain was 1 or 2 , indicating $1 R$ or $2 R$, respectively. The two factors were arranged in an unbalanced design between the cropping seasons: in 2017, the SPR and ADM treatments were applied with only $1 R$ and thus no $2 R$ treatments were present. In 2019, SPR was applied with $2 R$ and ADM was applied with either $1 R$ or $2 R$. The unbalancing of the complete dataset was carefully taken into account in the statistical analysis (see further).

\subsection{Equipment Used: Combines, Tractors, and Balers}

Two main kind of machines were involved in the wheat harvesting: a combine harvester for collection of the grain and a tractor-baler combination for baling of the residuals (straw and chaff). The combine harvester used in 2017 was a hybrid Fendt 9490, and a New Holland CX5.80 equipped with the Rekordverken Combi System for chaff recovery in 2019. The baling was performed in both cropping seasons by means of a New Holland roll baler 125 Combi driven by a New Holland T6.175 tractors in 2017 and a New Holland T210 tractor in 2019.

\subsection{Combi System Description}

The Combi System developed by Swedish machine manufacturer Rekordverken Sweden AB is installed downstream of the sieving unit of the combine harvester [20]. Regardless of the cleaning shoe system adopted, the Combi System only requires a dedicated opening for the husk discharge. At this point, the fan delivers the chaff to the Combi System which, in turn, channels it either towards the chopping system (then mixed with the straw and in theory baled together), or laterally to the straw swath (spread on the ground, which discard its ability of being baled).

The hybrid combine used in the 2017 had no additional beaters (only 1 beater or rotor) after the separating rotors. For this reason, both SPR and ADM treatments were marked as 1R. In the 2019 test, the combine used was equipped with an additional beater downstream of the cross separator rotor. Such additional beater could be switched off by allowing modulating of the process with one (1R) or two beaters or rollers $(2 \mathrm{R})$.

\subsection{Pre-Harvest Biomass Sampling}

Before grain harvesting, sample areas of $1 \mathrm{~m}^{2}$ each were randomly chosen and hand harvested at the ground level to score the potential total yield (grain + chaff + straw + stubble). Sampling areas close to the border were avoided to prevent edge effect. Plants were dissected on field for fresh weight of straw and spikes, then bagged and shipped to the CREA-IT laboratory for spike manual threshing and stubble, spike, chaff, and grain weight assessments. In the laboratory, grain was separated in a stationary thresher (Cicoria mod. Plot 2375) from the rest of the spike (sum of chaff, rachis, lemma, glumes, and palea) and weighed. The rest was weighed as a single by-product and referred to as chaff only. From all culm collected, 30 bunches of 10 randomly selected stems were collected. Relaying on the mean value of hundred stubble heights measured in a transversal transect drawn after the harvest, a cut was performed. The ratio between the weight of the part cut and the total weight of the bunch gave the percentage $(w / w)$ of stubble that remained on the ground. The corresponding amount of grain, chaff, straw, and stubble was calculated. In the 2017 cropping season, the straw samples collected were also split in 10-cm pieces and weighed. The distribution of the weight of the straw along the culm was measured. 


\subsection{Harvesting and Baling: Machines Performance}

Baling was done one day after grain harvesting. Figure 1 shows the combine harvester working in the SPR and ADM mode.

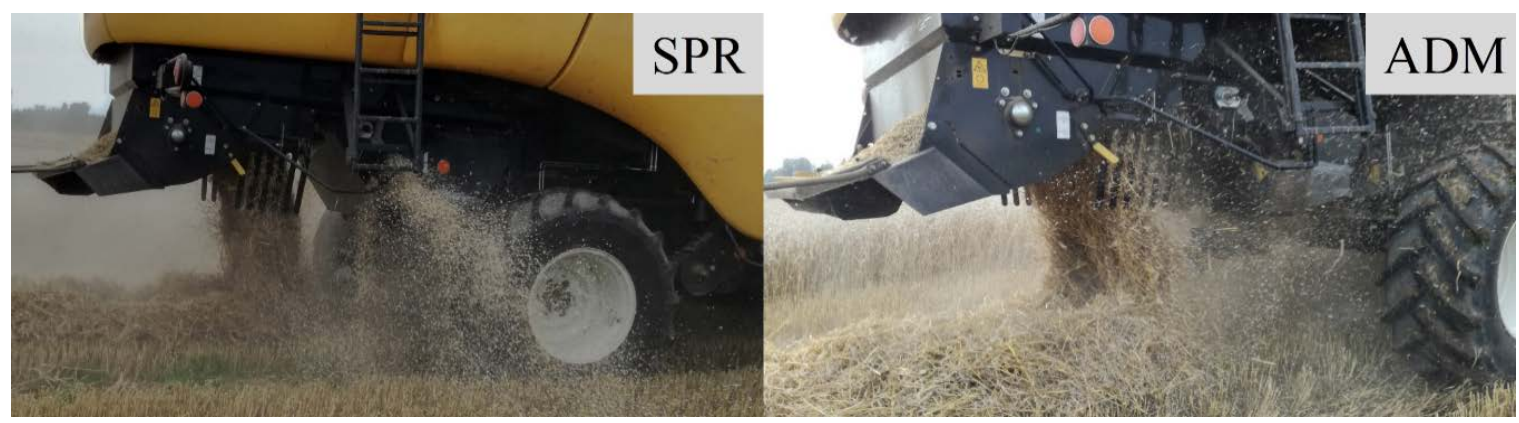

Figure 1. Chaff mixing strategies applied in the present study: the chaff was either spread (SPR, left panel) on the soil laterally to the straw swath by the combine harvester or it was admixed to the straw and released at the same time (ADM, right panel) (Source: CREA).

\subsubsection{Time Records}

In each experimental plot, the performances of the machinery was evaluated by studying the working times, according to the standard ASAE S496.2 [21]. The working times were measured and used to determine the actual and theoretical amount of area that can be served in the unit time by each machine. These were termed effective field capacity (EFC) $\left[\mathrm{ha} \mathrm{h}^{-1}\right]$ and theoretical field capacity (TFC) [ha $\mathrm{h}^{-1}$ ], respectively. The EFC is also computed by dividing the hectares processed by the operative time (OT), i.e., the raw time needed to complete the harvest, including accessory times. These accessory times include turning times, the time needed for maintenance, regulations, refueling, and unloading the hoppers, among others. The TFC is the theoretical maximum field capacity without the accessory times. Lastly, material capacity (MC) was computed as the quantity of grain or wheat residues harvested per time unit $\left[\mathrm{t} \mathrm{h}^{-1}\right]$.

\subsubsection{Fuel Consumption}

Fuel consumption was measured in both the combine harvester and the tractor towing the baler. In the 2017, the fuel consumption was measured using a graduated cylinder to refill the tank at the end of each plot. The volume of the fuel measured per plot was referred per hectare. The refilling procedure was carefully carried out in order to avoid possible biased readings. In the 2019, both machineries were equipped with an onboard computer providing real-time fuel consumption for $1 \mathrm{~h}^{-1}$. The instrument was cleared at the beginning of each plot and the reading was taken at the end of it. All the gathered data were used to define the performance of the machine and the operative costs.

\subsection{Post-Harvesting Analysis}

After straw harvesting, the following parameters were measured: mean bale fresh weight (the last bale on each plot was weighted but not taken into account for this variable), bale density, moisture content of chaff and straw during baling, and harvesting losses due to baling. Each bale was weighed for mean fresh weight and total fresh biomass yield per plot.

\subsubsection{Bulk Density}

In each plot, all bales were weighed singularl, and three of them were randomly selected and their sizes measured for volume assessment. Bulk density was successively calculated by dividing the mass in kilograms by the volume in cubic meter. The last bale in each plot was not taken into account in the bulk density calculation. In addition, non-completely filled bales (i.e., undersized bales) at the end of each plot were not taken into account in the statistical analyses on bale unit weight and density. 


\subsubsection{Moisture Content}

A sample was taken from one bale in each plot for moisture content determination by using a drill. The resulting moisture content was used to determine the dry matter (DM) yield of each plot. Moisture content was determined using the oven dry method described in the EN ISO 18134-2:2017 standard [22]. Moisture content in the grain, straw, and chaff were determined on three random subsamples.

Additionally, one sample per plot was taken from the swaths directly after combine harvesting. One grain sample was taken during the whole harvesting operation of the nine plots. It was dried at $105^{\circ} \mathrm{C}$ for $24 \mathrm{~h}$.

\subsection{Evaluation of Residue Harvest Losses}

During the test carried out in 2017, biomass losses were evaluated as the average of the residues collected. This was carried out by using a vacuum system in three random transects, each measuring $9.2 \mathrm{~m}$ long and $0.5 \mathrm{~m}$ wide. The transect collection was performed by splitting the $9.2-\mathrm{m}$ transect in three parts: a central part corresponding to the width of the baler pick-up collector and two lateral parts in which the straw and chaff could not be picked up by the baler. This allowed to compute, for the 2017 test only, two efficiency indexes, taking into account either the total residues (straw + chaff) deposited by the combine (referred as raw efficiency) or the sole residues that the baler was able to pick up (referred to as net efficiency).

In 2019 test, losses were estimated as the difference between theoretical biomass of grains, straw, and chaff collectable before the harvest (see Section 2.4) and the effective amount collected. Losses also included the amount of biomass lost as stubble.

\subsection{Statistical Analysis}

The experiment in the 2017 cropping season included a comparison between SPR and ADM, both subjected to one transversal threshing. In 2019, treatments included spreading with two rotors, ADM with $2 R$ or ADM with $1 R$. Notably, the 1 R experiment in 2019 was performed by excluding, but not turning off, the second rotor from receiving the straw and chaff. Thus, results on fuel consumption and derived traits also depend on the combine energy needed to move the unused rotor.

The two-years experiment was subjected to a unique general linear mixed model (GLMM) by the Glimmix procedure in the SAS/STAT 9.2 statistical package in which the role of CM (either SPR or $\mathrm{ADM}$ ), $\mathrm{RN}$ (either $1 \mathrm{R}$ or $2 \mathrm{R}$ ), and their interaction was analysed. This procedure can model non-normal data and correct for heteroscedasticity [23]. Restricted maximum likelihood was used to produce unbiased estimates of variance and covariance parameters.

To accommodate for the unbalancing of the experiment, a Kenward-Roger estimation of the denominator degrees of freedom of each error was used and least square means (LSmeans, see below for a definition) of the treatment distributions were computed. When a treatment was considered significant at $p<0.05$, LSmeans $\mathrm{p}$-differences were computed and corrected by the Tukey-Kramer adjustment at 0.05 . See the supplementary material in Saia et al. [24] for both a description of the procedure and the SAS package model applied.

To take into account both the variability of the growing seasons (referred as "year") and position of both the plot in each field and each bale within each plot, the analyses included various random factors depending on the variable measured. For variables relating to single straw bale, random factors included the cropping season, replicate within the cropping season, and the position of the bale in the field. For variables relating to the plot, random factors included the cropping seasonand replicate within cropping season. LSmeans were used instead of the means to compare the treatment effects. Briefly, LSmeans are estimation of a balanced population mean from an unbalanced data population. Thus, they estimate the corresponding mean in a factor level after taking into account both the distribution of the values of the variable within the level (fixed and random factors), and the distribution of the values within the population. In the results sections, data provided were the 
LSmeans of the treatments and the estimation of its standard error. The raw data means and their standard deviations were provided as supplementary material tables.

\section{Results}

\subsection{Grain and Straw Yields, Biomass Distribution in the Residues, Straw Traits, and Straw Harvesting Efficiency}

On average, the total biomass produced was $16,490 \mathrm{~kg}^{\mathrm{DW}} \mathrm{ha}^{-1}$, with a mean harvest index (i.e., the ratio between grain and total biomass) of 0.49 . In contrast to our expectation, grain yield was $10.6 \%$ higher in the SPR than ADM plots, on average (Tables 1 and S1).

Table 1. Results of the general linear mixed analysis of the wheat biomass fraction and efficiency of the harvesting procedures. During the combine harvesting, the wheat straw was subjected to the chaff mixture (CM): either by admixing the chaff with the straw (ADM) or spreading the chaff in the soil before the straw release (SPR). The procedures were performed by either using 1 or 2 rotors (1R or $2 R$, respectively). Since no interaction was detectable between factors, only LSmeans data per factor are displayed. See the text for the statistical analysis. Factors at $p<0.05$ are shown in bold.

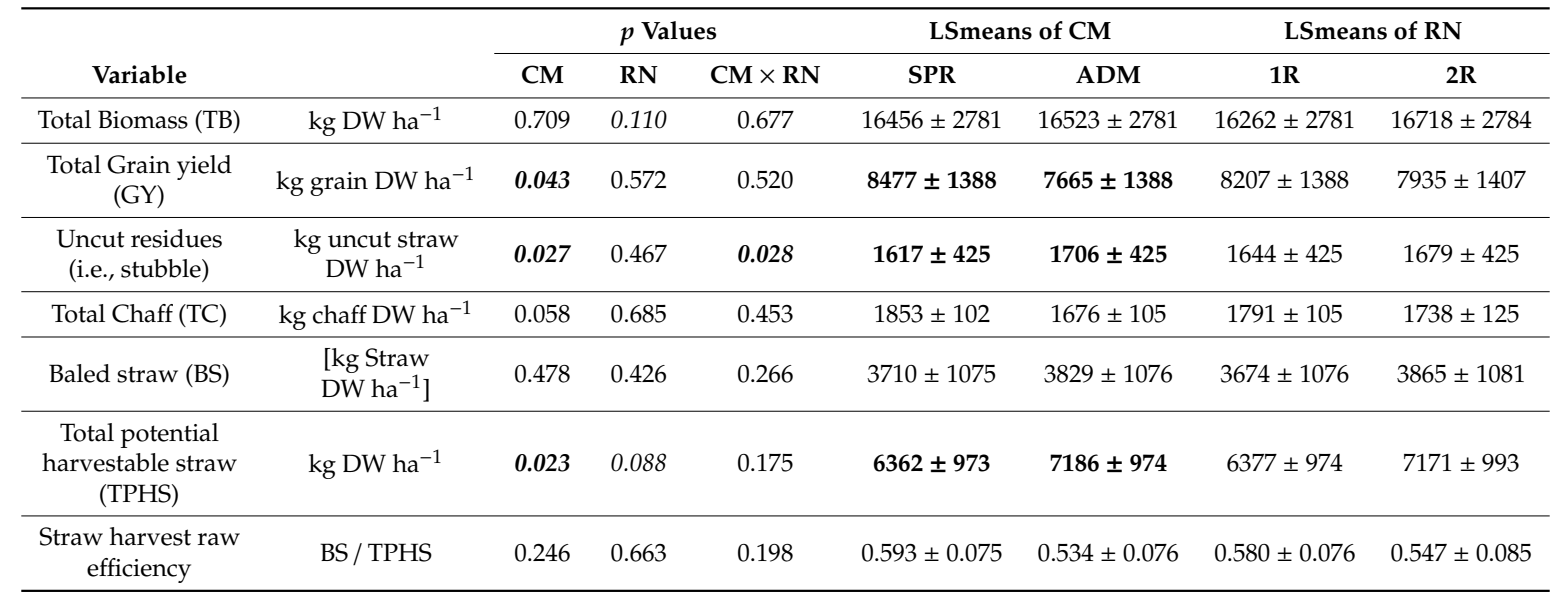

Such a difference was marginally significant (with the CM factor showing a $p=0.043$ ). Notably, such a difference cannot be attributed to the $\mathrm{CM}$ factor and must be considered a natural variation in the field. Nonetheless, it was taken into account in the further analyses. At the same time, the CM strategy strongly affected the total potential harvestable straw (TPHS), with ADM allowing to obtain $13.0 \%$ more TPHS compared to the SPR, although such an effect is very likely due to the higher grain yield in this latter treatment compared to ADM.

Straw harvest raw efficiency, i.e., the ratio between the straw baled and total residues (except stubble) available was $56.3 \%$, with no differences among treatments. In general, the treatments applied had a scarce effect on the biomass traits and straw harvest raw efficiency (Table 1) computed on the basis of the TPHS. In 2017, the straw harvest efficiency was computed by both a raw basis, as indicated above, and a net basis. The net harvest straw efficiency was computed by discarding from the analysis the amount of straw that fell outside of the baler collection line. Raw and net efficiencies were found to be strongly correlated (Figure 2).

In contrast, the effect of the $\mathrm{CM}$ on the fraction of biomass that was not harvested varied according to the RN (Table 1 and Figure 3). When using 1R, no differences were found between SPR and ADM, whereas using 2 rotors consisted of a slightly higher fraction of non-harvested biomass (i.e., the stubble) in ADM compared to SPR. Notably, such differences did not consist of a difference in the total DW of the straw baled, which however differed for the FW. In particular, ADM showed $4579 \mathrm{~kg}$ straw FW $\mathrm{ha}^{-1}$ and SPR $4243 \mathrm{~kg}$ straw FW ha ${ }^{-1}(p$ of $\mathrm{CM}=0.029 ; p$ of $\mathrm{RN}=0.097 ; p$ of the interaction $=0.909$ ). 


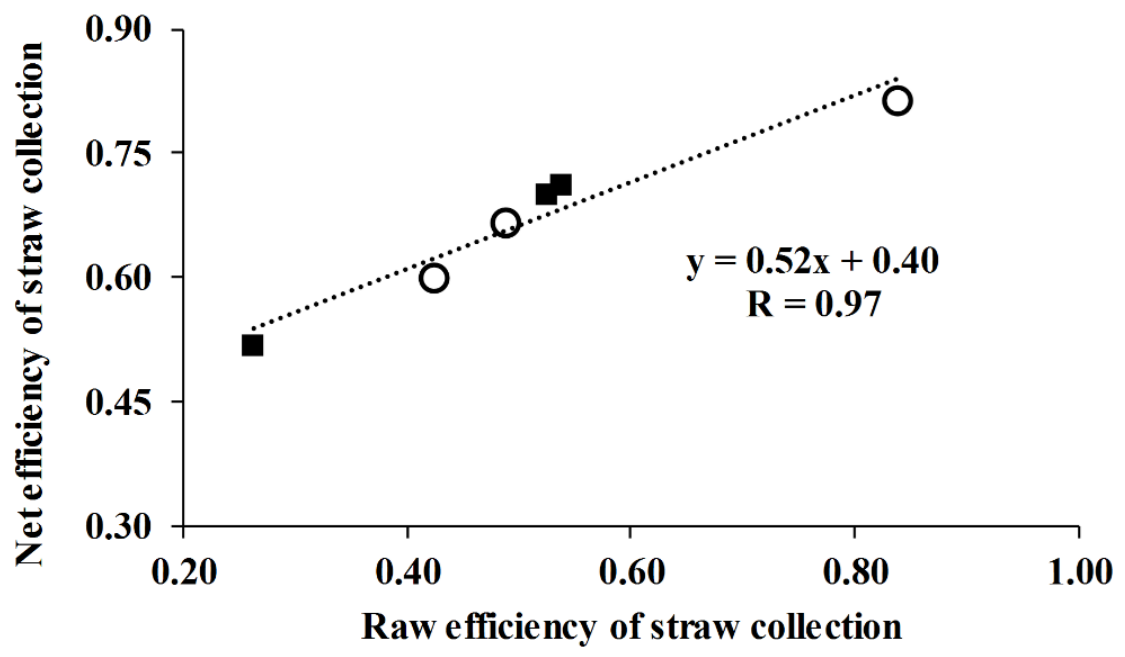

Figure 2. Correlation between net and raw straw efficiency collection in the 2017 experiment. Filled squares are for ADM treatments, and open circles for SPR treatments. The correlation coefficient is displayed.

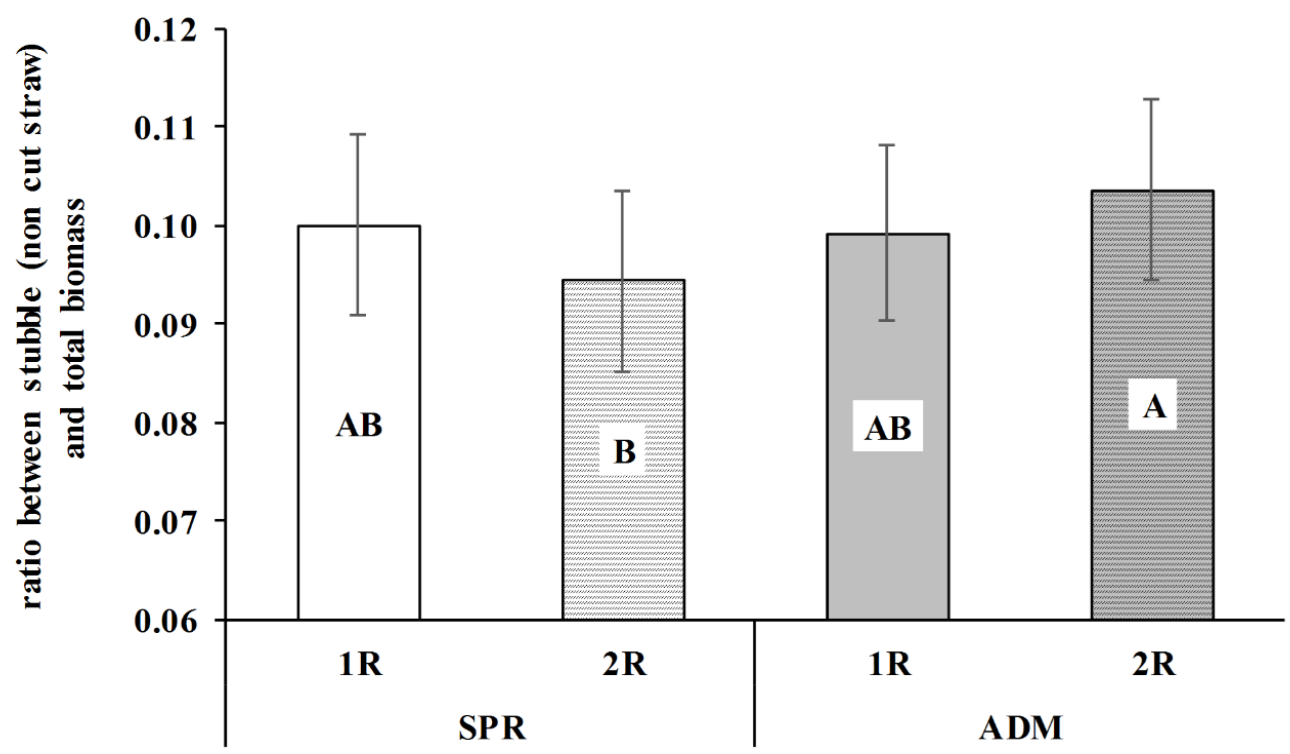

Figure 3. Ratio between stubble (i.e., uncut straw) and total biomass on varying the chaff management after grain threshing: either admixing the chaff with the straw (ADM, grey bars) or spreading the chaff in the soil before the straw release (SPR, white bars) and number of rotors for the threshing operation: either 1 (clean bars) or 2 (hatched bars), indicated as $1 \mathrm{R}$ or $2 \mathrm{R}$, respectively. Means with a letter in common cannot be considered different according to a conservative Tukey-Kramer test applied to the p differences of the LSmeans.

Biomass distribution along the culm was also measured in 2017 (Figure 4) showing a homogeneous distribution along the first $50 \mathrm{~cm}$ of the culm, which is abundantly higher than the cutting height, and a tendency to decline at the $50-\mathrm{cm}$ height.

Rotor number, but not the CM strategy, affected the bale and straw traits (Tables 2 and S2). In particular, $2 \mathrm{R}$ allowed for a $5.3 \%$ higher bale weight compared to $1 \mathrm{R}$. At the same time, $2 \mathrm{R}$ consisted of dramatically shorter straw pieces compared to $1 \mathrm{R}: 24.1 \%$ of length reduction, consisting of $9.0 \mathrm{~cm}$. 


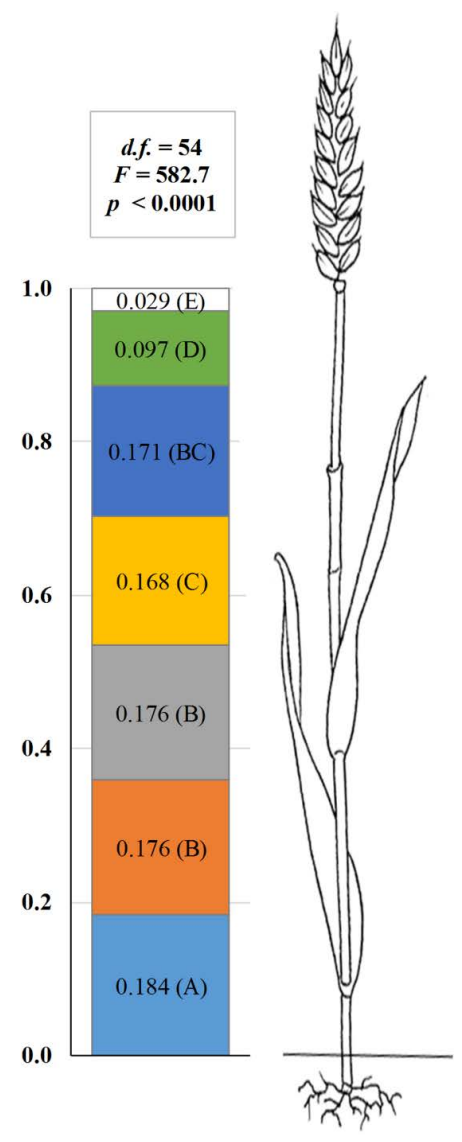

Figure 4. Biomass distribution along the total height of the straw (split by 10-cm pieces) in 2017. Each fraction represents a 10-cm piece, except for the upper fraction (white bar) that represents a 2-cm piece. Means with a letter in common cannot be considered different according to a Tukey-Kramer test applied to the $p$ differences of the LSmeans. The results of the statistical analysis are shown in the picture.

Table 2. Results of the general linear mixed analysis of the single bale traits (mean dry and fresh weight and density) in the complete dataset and length of straw pieces (in 2019, only). During the combine harvesting, the wheat straw was subjected to the chaff mixture (CM): either by admixing the chaff with the straw (ADM) or spreading the chaff in the soil before the straw release (SPR). The procedures were performed by either using 1 or 2 rotors ( $1 \mathrm{R}$ or $2 \mathrm{R}$, respectively). Since no interaction was detectable between factors, only LSmeans data per factors at $p<0.05$ are displayed. See the text for the statistical analysis. In 2019, arithmetic mean is shown since the dataset was balanced. Factors at $p<0.05$ are shown in bold, the estimation of the degrees of freedom (d.f.) by the Kenward-Roger procedure and the standard error (S.E.) are shown.

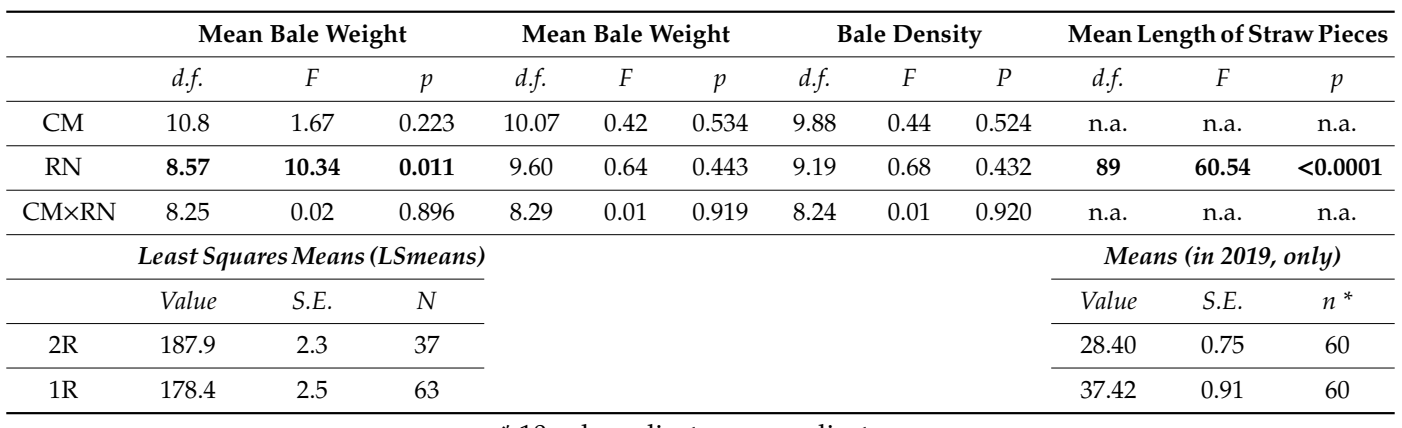

*10 sub-replicates per replicate. 
3.2. Efficiency of Combine Grain Harvesting and the Baling Procedures, and Fuel Consumption

Field efficiency (FE) of the grain harvesting procedures was markedly influenced by RN (Tables 3 and S3), with $1 \mathrm{R}$ harvested treatments showing an $8 \%$ absolute higher field efficiency than the $2 \mathrm{R}$ treatment. In contrast, neither the CM nor the RN affected the TFC, EFC, and fuel consumption.

The CM strategy also affected the material capacity of the combine and such an effect was evident, with SPR treatments allowing to collect $14.9 \%$ more grain in the same unit time compared to ADM.

On average, TFC and EFC were $3.72 \mathrm{ha} \mathrm{h}^{-1}$ and $2.28 \mathrm{ha} \mathrm{h}^{-1}$, respectively and the combine required 11.81 fuel $\mathrm{h}^{-1}$.

In contrast to the grain harvesting procedures, the straw baling procedures were not affected by the treatments applied (Tables 3 and S1). In particular, TFC and EFC of the baling operation resulted on average $3.96 \mathrm{ha} \mathrm{h}^{-1}$ and $2.01 \mathrm{ha} \mathrm{h}^{-1}$, thus consisting of a mean field efficiency of 0.51 . No information is available about the fuel needed for the baling procedure. 
Table 3. Results of the general linear mixed analysis of the grain harvesting and straw baling procedures. During the combine harvesting, the wheat straw was subjected to chaff mixture (CM): either by admixing the chaff with the straw (ADM) or spreading the chaff in the soil before the straw release (SPR). The procedures were performed by either using 1 or 2 rotors (1R or $2 \mathrm{R}$, respectively). Since no interaction was detectable between factors, only LSmeans data per factors are displayed. See the text for the statistical analysis. Factors at $p<0.05$ are shown in bold.

\begin{tabular}{|c|c|c|c|c|c|c|c|c|}
\hline & & \multicolumn{3}{|c|}{$p$ Values } & \multicolumn{2}{|c|}{ LSmeans of CM } & \multicolumn{2}{|c|}{ LSmeans of RN } \\
\hline & & $\mathbf{C M}$ & RN & $\mathbf{C M} \times \mathbf{R N}$ & SPR & ADM & 1R & $2 \mathbf{R}$ \\
\hline \multicolumn{9}{|c|}{ Data for the grain harvesting procedures } \\
\hline Theoretical Field Capacity (TFC) & {$\left[\right.$ ha $\left.\mathrm{h}^{-1}\right]$} & 0.69 & 0.17 & 0.41 & $3.68 \pm 1.66$ & $3.76 \pm 1.66$ & $3.51 \pm 1.66$ & $3.92 \pm 1.67$ \\
\hline Effective Field Capacity (EFC) & {$\left[\mathrm{ha} \mathrm{h}^{-1}\right]$} & 0.71 & 0.66 & 1.00 & $2.29 \pm 0.85$ & $2.27 \pm 0.85$ & $2.26 \pm 0.85$ & $2.30 \pm 0.85$ \\
\hline Field efficiency (FE) & EFC/TFC & 0.63 & 0.01 & 0.24 & $0.63 \pm 0.06$ & $0.62 \pm 0.06$ & $0.66 \pm 0.06$ & $0.58 \pm 0.06$ \\
\hline Fuel consumpion & {$\left[1 \mathrm{ha}^{-1}\right]$} & 0.81 & 0.11 & 0.37 & $11.8 \pm 2.0$ & $11.8 \pm 2.0$ & $12.1 \pm 2.0$ & $11.5 \pm 2.1$ \\
\hline Material Capacity & [t grain $\mathrm{h}^{-1}$ ] & 0.01 & 0.34 & 0.11 & $19.6 \pm 2.5$ & $17.1 \pm 2.5$ & $18.8 \pm 2.5$ & $17.8 \pm 2.5$ \\
\hline \multicolumn{9}{|c|}{ Data for the baling procedures } \\
\hline Mean ball weight & [kg Straw FW per bale] & 0.78 & 0.36 & 0.35 & $210 \pm 17$ & $211 \pm 17$ & $208 \pm 17$ & $212 \pm 17$ \\
\hline Bale density & [kg Straw FW m $\left.{ }^{-3}\right]$ & 0.75 & 0.34 & 0.33 & $134 \pm 17$ & $134 \pm 17$ & $133 \pm 17$ & $135 \pm 17$ \\
\hline Theoretical Field Capacity (TFC) & {$\left[\right.$ ha $\left.\mathrm{h}^{-1}\right]$} & 0.38 & 0.76 & 0.64 & $3.86 \pm 0.17$ & $4.06 \pm 0.15$ & $3.92 \pm 0.15$ & $3.99 \pm 0.17$ \\
\hline Effective Field Capacity (EFC) & {$\left[\right.$ ha $\left.\mathrm{h}^{-1}\right]$} & 0.70 & 0.49 & 0.49 & $1.98 \pm 0.29$ & $2.04 \pm 0.29$ & $1.92 \pm 0.29$ & $2.10 \pm 0.32$ \\
\hline Field efficiency (FE) & EFC/TFC & 0.81 & 0.48 & 0.61 & $0.52 \pm 0.07$ & $0.51 \pm 0.07$ & $0.49 \pm 0.07$ & $0.54 \pm 0.08$ \\
\hline Material Capacity & [t straw $\left.\mathrm{h}^{-1}\right]$ & 0.18 & 0.12 & 0.65 & $8.82 \pm 4.32$ & $9.50 \pm 4.32$ & $8.58 \pm 4.32$ & $9.74 \pm 4.33$ \\
\hline
\end{tabular}




\section{Discussion}

The above ground residual biomass of cereals has a high energy value and can have a high economic value. Nonetheless, it is an untapped by-product that could provide an extra amount of biomass for the production of bio-commodities. From this point of view, its collection should in theory be as high as possible, in order to reduce the fixed energetic costs of collection, as also recently suggested, taking into account that the producing bioenergy from the straw may have lower impacts compared to that from the grain [25] and that combining food and energy systems may allow for a further reduction of the environmental impact and to mitigate the climate-related fluctuations of the agricultural production and commodity value [26].

Concerns have arisen about the straw removal from the soil and its likely negative impact on soil organic carbon (SOC) accumulation. However, it is quite established that SOC accumulation mostly depends on the root carbon rather than above ground carbon [11] and that straw use for bioenergy processes can save various times the $\mathrm{CO}_{2}$ the soil is able to sequester as SOC [27]. In addition, no SOC loss was found depending on the straw removal in various environments in both short- and long-term experiments $[7,8]$.

In this work, a device developed to incorporate the chaff into the swath and thus allow its recovery as baled straw, in contrast to the most common operation of spreading it onto the soil, was tested. This device was tested in combination with a milder process, compared to a harsher threshing operation (i.e., $1 \mathrm{R}$ compared to $2 \mathrm{R}$, respectively), which can affect the length of the straw pieces and thus the straw aptness to be baled. Notably, the two operations were performed by taking the whole combine devices turned on. This implies that both the ADM and SPR mode had the chaff-to-straw mixer on, but it did not receive the material when in the SPR mode. Similarly, both $1 \mathrm{R}$ and $2 \mathrm{R}$ modes had the second rotor turned on, which did not receive material when in the $1 \mathrm{R}$ mode.

This implies that differences in the combine performance were likely due to the additional energy required to overcome the friction of the plant biomass being processed into the combine, rather than to the energy required to get the device turned on. Nonetheless, this was enough to produce a difference in the field efficiency (FE) of the system, with the $1 \mathrm{R}$ showing higher FE than the $2 \mathrm{R}$. In particular, it was shown that such a friction can be responsible for scarce energy demand by the combine [28-30], but it can still demand more time for the operator to allow the complete threshing of the grain and cutting of the straw. It should be, however, highlighted that field efficiency in this experiment likely differed from a normal cultivation due to the high time needed for turning and stopping compared in the plots, whose size was definitely smaller than that of most fields.

Nonetheless, similar behavior may have occurred when comparing the combine performance in the CM modes, where SPR showed a higher material capacity than ADM. Indeed, ADM consisted of higher amounts of both straw FW baled and TPHS. Therefore, the differences in the material capacity may have been due also to the higher amount of biomass the ADM mode had to process. In SPR, the chaff is spread laterally to the swath, and the chopper is bypassed, which also reduces the wear and energy consumption on the combine. It was excluded that such differences may have been due to a differential regulation by the combine driver of the cutting height since the stubble was slightly heavier $(+5.5 \%)$ in the ADM compared to the SPR; however, such a difference only corresponds to $0.8-1.1 \mathrm{~cm}$ of stubble, that may have been due to a local difference in soil-carrying capacity. In addition, the biomass distribution in the culm was strongly homogeneous below $50 \mathrm{~cm}$ height and, above all, this may have not produced a difference in the grain harvested, thus suggesting that local conditions in the ADM plots may have affected the stubble biomass. This confirms the results by Boyden et al. [31] who found that stubble height is not directly and linearly related to the straw baled, despite their stubble height being $50 \%-100 \%$ more than the one in the present study. It was also excluded that difference in the grain harvested could have been due to a higher loss of grain as non-threshed material in the ADM compared to the SPR since no grain was found in the soil after the combine harvesting or into the bales when these were sampled to be analysed. Notably, these differences between SPR and ADM did not consist of a difference in the combine fuel demand. 
In contrast to the combine, the treatments applied did not affect baler performance. However, the efficiency of straw removal (i.e., the straw removed per unit total residues available) dramatically differed with the strategy of computation of the efficiency. When taking into account the whole TPHS, including that which fell out of the baler swaths, such an efficiency was $16 \%$ lower than when taking into account the only residue fraction in the baler collection swath.

Similar results of the percentage of straw removed were found by other authors [32-34]. In particular, Bergonzoli et al. [34] also found similar effects on machine performance by varying the chaff collection device. A higher percentage of straw removed was found in the present study than others [7,35]. This can explain the lack of difference among treatments. Indeed, in the Lafond et al. [7] experiment, both grain and straw yields were $65 \%$ and $75 \%$ lower, respectively, when compared to the present experiment, and straw losses ranging from $60 \%$ to $78 \%$. In conditions of low yields and high straw losses, little additional straw recovery can determine marked difference in the percentage of straw baled. In addition, SPR and ADM did not differ by mean bale weight, whereas $2 R$ consisted of heavier bales than $1 R$. Since $2 R$ consisted of definitely shorter straw pieces, this may be an indirect outcome of a better baling procedure. This can explain the higher bale unit DW in the $2 R$ than $1 R$. Lack of differences in the bale unit weight or density by the chaff management systems could have been due to the scarce amount of chaff compared to the straw, which resulted in $23-29 \%$ of the TPHS. Similar or slightly higher results were found by others $[7,36]$.

\section{Conclusions}

In conclusion, alternative management strategies of the chaff and the degree of straw cutting into the combine scarcely affected both grain harvesting and baling procedure performances. Chaff mixing with the straw allowed for slightly higher straw FW yields $\left(+336 \mathrm{~kg}\right.$ straw $\left.\mathrm{FW} \mathrm{ha}^{-1}\right)$, but it may slightly reduce the material capacity of the combine. In contrast, using 1 rotor in the threshing line of the combine can increase combine field efficiency, but it can reduce the bale unit weight, which can have drawbacks in the energy demand of the pipeline of the bale logistics. The strategies applied in the present study consisted of straw losses of $41-47 \%$. If considering that chaff represented $23-29 \%$ of the total residues, this implies that an efficient collection of the chaff can allow halving the loss of residues. This could occur without loss in performance of the whole harvesting, baling, and bale handling chain, if considering that chaff management can represent a negligible cost compared to the fixed costs of the whole baling procedure and bale handling [14]. However, further studies are needed to optimise both chaff and the straw recoveries, with special emphasis on the ability to collect it separately from the straw within the combine or better incorporating it into the straw before baling. A main limitation of the present study indeed is the relatively high straw biomass in this field, which may have masked the role of the chaff management, and limited information on the rotor effects.

Supplementary Materials: The following are available online at http://www.mdpi.com/1996-1073/13/7/1766/s1, Table S1. Data of the grain, biomass and efficiencies, baling procedures, and grain harvesting procedures in 2017 and 2019 (means \pm standard deviations), Table S2. Data of the bale traits in 2017 and 2019 (means \pm standard error).

Author Contributions: Conceptualization, A.S., L.P., C.G., M.S.; methodology, A.S.; validation A.S.; formal analysis, S.S. and A.S.; data curation, S.S.; writing-original draft preparation, S.S., W.S. and A.S.; writing-review and editing, A.S., L.P., C.G. and M.S.; supervision, L.P.; funding acquisition, L.P. All authors have read and agreed to the published version of the manuscript.

Funding: This research was supported by AGROinLOG project funded by the European Union's Horizon 2020 research and innovation programme under Grant Agreement No. 727961 (http://agroinlog-h2020.eu/en/home/).

Acknowledgments: The authors thank Francesco Latterini for GIS analysis of the experimental fields, and Sandu Lazar (CREA) and Martin Knicky (RISE) for support during the field data collection. Trials were performed at Vattholman and Alunda (Uppsala, Sweden). The authors thank the hosting farmers, brothers Torbjörn and Krister Larsson in 2017, and Ted Ericsson in 2019 for their valuable help provided in the field activities.

Conflicts of Interest: The authors declare that they have no financial interests or personal relationships with the brands cited. Furthermore, the funders had no role in the design of the study; in the collection, analyses, or interpretation of data; in the writing of the manuscript, or in the decision to publish the results. 


\section{References}

1. Food and Agriculture Organization. FAOSTAT Data. Available online: http://www.fao.org/faostat/en/\#home (accessed on 12 February 2020).

2. Scarlat, N.; Dallemand, J.F.; Monforti-Ferrario, F.; Nita, V. The role of biomass and bioenergy in a future bioeconomy: Policies and facts. Environ. Dev. 2015, 15,3-34. [CrossRef]

3. EU 2015/1513 ILUC Directive. Off. J. Eur. Union 2015, 20-30.

4. European Parliament. Report on a 2030 Framework for Climate and Energy Policies (20132135(INI)); European Parliament: Brussels, Belgium, 2014.

5. Stelte, W.; Sanadi, A.R.; Shang, L.; Holm, J.K.; Ahrenfeldt, J.; Henriksen, U.B. Recent developments in biomass pelletization-A review. BioResources 2012, 7, 4451-4490.

6. McCartney, D.H.; Block, H.C.; Dubeski, P.L.; Ohama, A.J. The composition and availability of straw and chaff from small grain cereals for beef cattle in western Canada. Can. J. Anim. Sci. 2006, 86, 443-455. [CrossRef]

7. Lafond, G.P.; Stumborg, M.; Lemke, R.; May, W.E.; Holzapfel, C.B.; Campbell, C.A. Quantifying Straw Removal through Baling and Measuring the Long-Term Impact on Soil Quality and Wheat Production. Agron. J. 2009, 101, 529-537. [CrossRef]

8. Ventrella, D.; Stellacci, A.M.; Castrignanò, A.; Charfeddine, M.; Castellini, M. Effects of crop residue management on winter durum wheat productivity in a long term experiment in Southern Italy. Eur. J. Agron. 2016, 77, 188-198. [CrossRef]

9. Rush, C.M. Effects of Wheat Chaff and Tillage on Inoculum Density of Pythium ultimum in the Pacific Northwest. Phytopathology 1986, 76, 1330. [CrossRef]

10. Shirtliffe, S.J.; Entz, M.H. Chaff collection reduces seed dispersal of wild oat (Avena fatua) by a combine harvester. Weed Sci. 2005, 53, 465-470. [CrossRef]

11. Rasse, D.P.; Rumpel, C.; Dignac, M.-F. Is soil carbon mostly root carbon? Mechanisms for a specific stabilisation. Plant Soil 2005, 269, 341-356. [CrossRef]

12. Santhi, C.; Srinivasan, R.; Arnold, J.G.; Williams, J.R. A modeling approach to evaluate the impacts of water quality management plans implemented in a watershed in Texas. Environ. Model. Softw. 2006, 21, 1141-1157. [CrossRef]

13. Panagos, P.; Borrelli, P.; Meusburger, K.; Alewell, C.; Lugato, E.; Montanarella, L. Estimating the soil erosion cover-management factor at the European scale. Land Use Policy 2015, 48, 38-50. [CrossRef]

14. Unger, J.S.; Glasner, C. Cost analysis of chaff harvesting concepts in Germany. Agronomy 2019, 9, 579. [CrossRef]

15. Pari, L.; Alfano, V.; Scarfone, A.; Bergonzoli, S.; Suardi, A.; Lazar, S. Best available technologies to harvest cereal chaff. In Proceedings of the 26th European Biomass Conference and Exhibition (EUBCE), Copenhagen, Denmark, 14-18 May 2018.

16. Muth, D.J.; Bryden, K.M. An integrated model for assessment of sustainable agricultural residue removal limits for bioenergy systems. Environ. Model. Softw. 2013, 39, 50-69. [CrossRef]

17. Sahoo, K.; Hawkins, G.L.; Yao, X.A.; Samples, K.; Mani, S. GIS-based biomass assessment and supply logistics system for a sustainable biorefinery: A case study with cotton stalks in the Southeastern US. Appl. Energy 2016, 182, 260-273. [CrossRef]

18. Suardi, A.; Bergonzoli, S.; Alfano, V.; Scarfone, A.; Pari, L. Economic Distance to Gather Agricultural Residues from the Field to the Integrated Biomass Logistic Centre: A Spanish Case-Study. Energies 2019, 12, 3086. [CrossRef]

19. Agroinlog Integrated Biomass Logistic Centres for the Agro-Industry. EU Horizon 2020 Research and Innovation Programme-Grant Agreement No 727961. Available online: http://agroinlog-h2020.eu/en/home/ (accessed on 17 January 2020).

20. Persson, S.J. Combine Harvester Having Astraw Chopper and Husk Discharger. U.S. Patent 6,656,038, 2 December 2003.

21. American Society of Agricultural Engineers. ASAE EP496.2 Agricultural Machinery Management. $A S A E$ Stand. 2000, 344-349.

22. EN 14774-1 Solid Biofuels_Determination of Moisture Content_Oven Dry Method-Part 1: Total MoistureReference Method; International Standard Organization: Geneva, Switzerland, 2009; ISBN 5935522004. 
23. Schabenberger, O. Introducing the Glimmix Procedure for Generalized Linear Mixed Models. SUGI 30 Proc. 2005, 1-20.

24. Saia, S.; Aissa, E.; Luziatelli, F.; Ruzzi, M.; Colla, G.; Ficca, A.G.; Cardarelli, M.; Rouphael, Y. Growth-promoting bacteria and arbuscular mycorrhizal fungi differentially benefit tomato and corn depending upon the supplied form of phosphorus. Mycorrhiza 2020, 30, 133-147. [CrossRef]

25. Lantz, M.; Prade, T.; Ahlgren, S.; Björnsson, L. Biogas and Ethanol from Wheat Grain or Straw: Is There a Trade-Off between Climate Impact, Avoidance of iLUC and Production Cost? Energies 2018, 11, 2633. [CrossRef]

26. Xu, Y.; Lehmann, L.M.; García de Jalón, S.; Ghaley, B.B. Assessment of Productivity and Economic Viability of Combined Food and Energy (CFE) Production System in Denmark. Energies 2019, 12, 166. [CrossRef]

27. Powlson, D.S.; Riche, A.B.; Coleman, K.; Glendining, M.J.; Whitmore, A.P. Carbon sequestration in European soils through straw incorporation: Limitations and alternatives. Waste Manag. 2008, 28, 741-746. [CrossRef] [PubMed]

28. Baruah, D.C.; Panesar, B.S. Energy Requirement Model for a Combine Harvester, Part I: Development of Component Models. Biosyst. Eng. 2005, 90, 9-25. [CrossRef]

29. Veikle, E.E. Modeling the Power Requirements of a Rotary Feeding and Cutting System. Ph.D. Thesis, University of Saskatchewan, Saskatoon, SK, Canada, 2011.

30. Burrough, D. Power requirements of combine drives. Agric. Eng. 1954, 35, 15-18.

31. Boyden, A.; Hill, L.; Leduc, P.; Wassermann, J. Field Tests to Correlate Biomass, Combine Yield and Recoverable Straw; Saskatchewan Agriculture \& Food, Agriculture Development Fund; Prairie Agricultural Machinery Institute: Regina, SK, Canada, 2001.

32. Opoku, G.; Vyn, T.J. Wheat residue management options for no-till corn. Can. J. Plant Sci. 1997, 77, $207-213$. [CrossRef]

33. Campbell, C.A.; Selles, F.; Lafond, G.P.; Zentner, R.P. Adopting zero tillage management: Impact on soil $\mathrm{C}$ and $\mathrm{N}$ under long-term crop rotations in a thin Black Chernozem. Can. J. Soil Sci. 2001, 81, 139-148. [CrossRef]

34. Bergonzoli, S.; Suardi, A.; Rezaie, N.; Alfano, V.; Pari, L. An Innovative System for Maize Cob and Wheat Chaff Harvesting: Simultaneous Grain and Residues Collection. Energies 2020, 13, 1265. [CrossRef]

35. Campbell, C.A.; Lafond, G.P.; Zentner, R.P.; Biederbeck, V.O. Influence of fertilizer and straw baling on soil organic matter in a thin black chernozem in western Canada. Soil Biol. Biochem. 1991, 23, 443-446. [CrossRef]

36. McClellan, R.C.; Nelson, T.L.; Sporcic, M.A. Measurements of residue to grain and relative amounts of straw, chaff, awns and grain yield of wheat and barley varieties common to eastern Washington. In STEEP-Conservation Concepts and Accomplishments. 1986 STEEP Annu. Rev.; Elliot, L.F., Ed.; Washington State Univ: Pullman, WA, USA, 1987; pp. 617-624. 